\title{
RELAÇÕES INTERATIVAS E ESTRUTURAS DE GOVERNANÇA NO ARRANJO PRODUTIVO LOCAL DE TRANSFORMADOS PLÁSTICOS DE SANTA CATARINA
}

\author{
Carla C. R. de Almeidal \\ Silvio A. F. Cario
}

\section{Resumo}

Este artigo tem por objetivo verificar como as ações desenvolvidas pelos agentes do arranjo produtivo local de transformados plásticos da região Norte do Estado de Santa Catarina-Brasil estão contribuindo para a construção e a sustentação de vantagens competitivas dinâmicas. Nesse sentido, a partir da literatura sobre cooperação e estruturas de governança em arranjos produtivos locais, analisam-se as relações interativas das empresas do arranjo. Os resultados obtidos com base na pesquisa de campo, composta por 33 empresas pertencentes aos segmentos de embalagens plásticas e artefatos diversos de plásticos, apontam que, dentre as relações interativas dos agentes destacam-se as formas de cooperação vertical e as relações de subcontratação, resultando em diversas formas de governança, demonstrando que as empresas beneficiam-se, principalmente, de vantagens locacionais passivas.

Palavras-chaves: Arranjos Produtivos Locais, Governança, Indústria de Produtos de Plástico.

Classificação JEL: L, L2, L20, L23

Mestre em Economia pela Universidade Federal de Santa Catarina - UFSC - e Doutoranda em Economia pela Universidade Federal de Pernambuco - UFPE. Professora Assistente A vinculada ao Departamento de Economia da Universidade Federal de Mato Grosso - UFMT. E:mail: carlalmeidarosa@gmail.com

2 Doutor em Ciências Econômicas pela Universidade Estadual e Campinas

Prof. Associado III vinculado ao Departamento de Economia e Relações Internacionais da Universidade Federal de Santa Catarina - UFSC. E-mail: fecario@yahoo.com.br 


\section{INTRODUÇÃO}

As empresas inseridas em arranjos produtivos locais (APLs) usufruem de benefícios diversos, em virtude das vantagens locacionais relacionadas à infraestrutura existente, relações comerciais e produtivas, qualificação dos trabalhadores, entre outras. Porém, a construção de vantagens competitivas dinâmicas depende de ações empreendidas com objetivos comuns, que sejam coordenadas pelos próprios agentes locais. Nesse particular, as atividades de cooperação, as instituições e estruturas de governança existentes no arranjo determinam, em última instância, o alcance de uma eficiência coletiva ativa.

Em Santa Catarina, existe uma aglomeração produtiva direcionada a produção de vários tipos de plásticos, sobretudo industriais. Apesar da predominância de micro e pequenas empresas (MPEs), 86,37\%, encontram-se presentes médias e de grandes empresas, com registro de 4 das 10 maiores empresas do país neste segmento. Dada a relevância deste APL, busca-se, neste trabalho, identificar e analisar os processos interativos e a estrutura de governança do APL de produtos transformados de plástico da região Norte do Estado de Santa Catarina. Para tanto, o texto encontra-se dividido em 6 seções, sendo que nesta $1^{\mathrm{a}}$. seção apresenta-se o seu objetivo; na $2^{\mathrm{a}}$. seção discutem-se os principais conceitos e terminologias utilizados no trabalho, embasando-se no tratamento teórico-analítico sobre aglomerações setoriais de empresas com predominância de MPEs; na $3^{\mathrm{a}}$. seção expõem-se os procedimentos metodológicos; enquanto na $4^{\mathrm{a}}$. seção analisam-se as relações interativas das empresas, bem como a estrutura de governança; e por fim, na $5^{\mathrm{a}}$. seção, encontram-se as conclusões.

\section{COOPERAÇÃO E ESTRUTURAS DE GOVERNANÇA EM ARRANJOS PRODUTIVOS LOCAIS: ELEMENTOS TEÓRI- COS-ANALÍTICOS}

A teoria recente sobre distritos industriais aponta as especificidades presentes nessas concentrações industriais que permitem a eficiência produtiva em pequena escala e tornam tais localidades referência em nível mundial. Assim, destacam-se as características em termos de identidade sóciocultural, que facilita a cooperação entre os agentes; a alta divisão do trabalho inter e intrassetorial; mão-de-obra especializada qualificada; presença de 
instituições diversas de apoio, entre outras, que possibilitam externalidades positivas para as empresas localizadas nos distritos. Uma particularidade, presente nos distritos e raramente observadas em outras localidades, diz respeito ao alto grau de cooperação entre os agentes econômicos, que permite o alcance de vantagens que extrapolam as externalidades acidentais, verificando-se uma situação de eficiência coletiva ativa ou deliberada.

A abordagem sobre APLs surge, então, no sentido de adaptar a teoria dos distritos industriais à realidade das aglomerações produtivas localizadas nos países em desenvolvimento, enfocando os aspectos de proximidade territorial, aprendizado coletivo e cooperação. Desse modo, considera-se que a cooperação e a confiança elevada "não são condições necessárias e nem mesmo suficientes para a constituição de um APL" (SANTOS e outros, 2004a, p. 41) e, portanto, admite-se a sua ocorrência mesmo em condições incipientes de cooperação entre os agentes.

Mesmo diante de um conceito abrangente, tem-se que a principal diferença entre uma aglomeração de empresas e um arranjo produtivo relacionase ao seu grau de territorialidade e às vantagens locacionais derivadas. A territorialização "é definida como um conjunto de atividade econômica que é dependente de recursos específicos do ponto de vista territorial" e não estão disponíveis em outros lugares (STORPER, 1996 como citado em VARGAS, 2002 b, p. 69). Tais recursos abrangem tanto ativos materiais específicos, como também externalidades provenientes de inter-relações possibilitadas pela proximidade territorial entre os atores locais. Santos e outros (2004b, p.163) afirmam que são as pequenas empresas que mais dependem da localização e da concentração produtiva, em função dos obstáculos enfrentados pelas mesmas, tais como os altos custos de relocalização das plantas produtivas e as dificuldades em obterem escalas mínimas de produção para se "suprir de determinados serviços e externalidades que encontram em condições facilitadas e seguras no local atual e podem não encontrar em outros locais". As empresas de menor porte também são beneficiadas pela disponibilidade e difusão das informações no local, muitas geradas por empresas de maior porte, que permitem upgrade tecnológico das pequenas. Assim, será maior o grau de territorialização do arranjo quanto maior for o grau de enraizamento dos ativos locais, principalmente, as relações entre os agentes e as suas capacitações tácitas, que viabilizam a atividade econômica do APL e não estão disponíveis em outras localidades. 
A influência das instituições e da governança local no desenvolvimento das aglomerações produtivas tem sido enfatizada por diversos autores (CASSIOLATO e LASTRES, 2002; HUMPHREY e SCHMITZ, 2001; SUZIGAN e outros, 2002; VARGAS, 2002a, 2002b). Nesse contexto, governança diz respeito a coordenação da atividade produtiva, através de práticas efetuadas por diversos atores do arranjo produtivo, tais como empresas, instituições, entidades representativas, trabalhadores ou o próprio Estado. De acordo com Vargas (2002a, p.12), estruturas de governança referem-se aos “diferentes modos de coordenação que envolve atividades interdependentes associadas tanto à organização de fluxos de produção como ao processo de geração, disseminação e uso de conhecimentos".

É frequente a ocorrência de relações de poder entre os agentes, devido à existência de firmas coordenadoras ou líderes, cujos ativos-chaves permitem imposição de seus interesses aos outros participantes e, muitas vezes, faz com que estas apropriem-se assimetricamente das externalidades positivas advindas da aglomeração produtiva. Contudo, esse fato não exclui a possibilidade de outras empresas usufruírem das externalidades positivas geradas, sendo que os ganhos das economias externas serão maiores e mais igualitários quanto maior for o grau de organização e de cooperação entre as firmas (CAMPOS, 2003; HUMPHREY e SCHMITZ, 2001).

Vargas (2002a, p.13) sugere que a análise da estrutura de governança deve ser realizada a partir da identificação: (a) dos principais atores locais ou externos, que exerçam influência no arranjo produtivo em questão, tais como empresas inseridas, as organizações formais de representação e as organizações pertencentes à infraestrutura de apoio, ensino e tecnologia; (b) do papel desempenhado pelo desenho institucional na mediação das relações de poder, caracterizado pelos resultados da atuação das organizações formais, assim como pelo papel das regras e rotinas vinculadas ao contexto cultural e histórico local, e (c) da relevância da infraestrutura educacional e tecnológica, mediante a avaliação da eficácia dessas instituições em “organizar e coordenar os fluxos de informações e conhecimento relevantes para o processo de capacitação produtiva e inovativa de atores locais".

Por sua vez, Storper e Harrison (1994) sugerem uma tipologia sobre estruturas de governança, utilizando o termo "sistemas de produção" para definir a estrutura de coordenação formada a partir de relações horizontais 
e verticais entre as empresas. Tais relações podem ser governadas por mecanismos de mercado ou resultar de processos interativos dos agentes. Nesse processo, estabelecem-se, nos arranjos produtivos locais, relações de liderança e hierarquia exercidas por alguns agentes, cujas estruturas de governança podem ser definidas de três formas: (i) all ring no core (anel sem núcleo); (ii) core-ring with coordinating firm (anel-núcleo, com empresa coordenadora); e (iii) core-ring with lead firm (anel-núcleo, com empresa líder). Os autores referenciados expõem, ainda, o tipo de governança all core, que não se aplica a casos de aglomerações produtivas, pois refere-se à existência de uma única grande empresa verticalizada.

A estrutura de governança all ring no core é caracterizada pela ausência de uma empresa líder permanente, conformando-se, então, uma relação entre iguais e sem hierarquia entre as firmas locais. Essa forma de governança é raramente verificada empiricamente e têm-se como exemplo principal os distritos industriais italianos até fins da década de 80 (SCHMITZ, 1997; SUZIGAN e outros, 2002). Por sua vez, sistemas produtivos nos quais prevalecem a estrutura core-ring with coordinating firm são marcados por algum grau de hierarquia e assimetria entre os agentes, sendo que a influência sistêmica de algumas firmas é limitada, por não determinar, necessariamente, a sobrevivência das outras empresas. Segundo Storper e Harrison (1994, p.177), a empresa coordenadora "ocupa uma posição dominante: é o agente motor do sistema input-output, mas não pode sobreviver sozinha, nem condicionar a existência das outras empresas do sistema". Os limites enfrentados pelas firmas coordenadoras devem-se a incapacidade delas "em assumir internamente as tarefas que são realizadas pelos outros participantes do processo" (SUZIGAN e outros, 2002, p.5).

$\mathrm{Na}$ governança do tipo core-ring with lead firm, a firma líder é dominante e as ações das outras empresas dependem dela, enquanto a líder é independente dos seus fornecedores e distribuidores. O alto grau de hierarquia deve-se ao fato de a empresa líder ser "largamente independente de seus fornecedores e subcontratados" (STORPER e HARRISON, 1994, p.177). Assim, a facilidade de substituir seus fornecedores e subcontratados faz com que as líderes tenham a possibilidade de remodelar sua periferia (ou anel) e, então, condicionar "a existência de certo número de parceiros" (STORPER e HARRISON, 1994, p.177). 


\section{PROCEDIMENTOS METODOLÓGICOS}

A análise dos processos interativos e das estruturas de governança do APL de produtos transformados de plásticos da região Norte do Estado de Santa Catarina-Brasil respaldou-se em pesquisa de campo, a partir de uma amostra de empresas, estratificada por porte empresarial e atividade industrial. A definição dos municípios que compõem o APL baseou-se, primeiramente, na delimitação da microrregião de Joinville, conforme classificação do Instituto Brasileiro de Geografia e Estatística (IBGE). Os mesmos foram classificados pelo critério do Quociente Locacional (QL), que indica a especialização produtiva do município ou região em determinada atividade, em comparação à especialização do país nessa mesma atividade (BRITTO; ALBUQUERQUE, 2002). Os municípios classificados foram: Araquari, Corupá, Guaramirim, Jaraguá do Sul, Joinville e Massaranduba, que possuem especialização produtiva em todos os subsetores, nos quais os mesmos possuem estabelecimentos.

A Tabela 1 apresenta informações sobre o número de empresas, quantidade de empregados, QL por sub-segmento da indústria de plástico, tanto para o arranjo em análise como do Brasil, considerando os anos 2005 e 2011. Observa-se que a participação relativa do setor, bem como o número total de trabalhadores formais e de estabelecimentos encontrados no arranjo são superiores quando comparados à média da indústria nacional, confirmando a especialização produtiva local.

Cabe ressaltar ainda que os números do último ano, 2011, apresentam, tanto em relação ao arranjo quanto em relação ao país, participação relativa dos segmentos produtivos muito próxima do primeiro ano em referência, 2005. Assim sendo, passados 6 anos entre 2005 e 2011, os dados referendam pouca mudança nas informações quantitativas, justificando assim, o estudo realizado em 2006 sob base de dados de 2005.

Tabela 1: Índice de especialização, participação no emprego e no número de estabelecimentos dos sub-setores da indústria de transformação de produtos de material plástico - arranjo produtivo local da região Norte de Santa Catarina e Brasil, 2005 e 2011 


\begin{tabular}{l|c|c|c|c|c|c|c|c|c}
\hline & \multicolumn{5}{|c|}{ Emprego 2005 } & \multicolumn{3}{c}{ Estabelecimentos 2005 } \\
\cline { 2 - 10 } $\begin{array}{l}\text { Classe CNAE classe } \\
\text { QL }\end{array}$ & $\begin{array}{c}\text { PFT } \\
\text { APL }\end{array}$ & $\begin{array}{c}\text { classe } \\
\text { nFT do } \\
\text { APL }\end{array}$ & PFT BR & $\begin{array}{c}\text { PFT } \\
\text { APL } \\
\text { PFT } \\
\text { BR }\end{array}$ & $\begin{array}{c}\text { ESTAB. } \\
\text { APL } \\
\text { no total } \\
\text { ESTAB. do } \\
\text { APL }\end{array}$ & $\begin{array}{c}\text { ESTAB. } \\
\text { BR }\end{array}$ & $\begin{array}{c}\text { ESTAB, } \\
\text { APL / } \\
\text { ESTAB. } \\
\text { BR }\end{array}$ \\
\hline $\begin{array}{l}\text { Fabricação } \\
\text { de laminados } \\
\text { planos e } \\
\text { tubulares } \\
\text { plástico }\end{array}$ & 3,87 & 297 & $3,29 \%$ & 12.970 & $2,29 \%$ & 7 & $4,55 \%$ & 344 & $2,03 \%$ \\
$\begin{array}{l}\text { Fabricação de } \\
\text { embalagem } \\
\text { de plástico }\end{array}$ & 1,77 & 964 & $10,66 \%$ & 92.064 & $1,05 \%$ & 26 & $16,88 \%$ & 2.688 & $0,97 \%$ \\
\hline $\begin{array}{l}\text { Fabricação } \\
\text { de artefatos } \\
\text { diversos de } \\
\text { plástico }\end{array}$ & 8,89 & 7.780 & $86,05 \%$ & 147.897 & $5,26 \%$ & 121 & $78,57 \%$ & 5.812 & $2,08 \%$ \\
$\begin{array}{l}\text { Fabricação de } \\
\text { calçados de } \\
\text { plásticos }\end{array}$ & - & 0 & $0,00 \%$ & 26.819 & $0,00 \%$ & 0 & $0,00 \%$ & 182 & $0,00 \%$ \\
\hline $\begin{array}{l}\text { Total setor } \\
\text { Total }\end{array}$ & 5,46 & 9.041 & $100,00 \%$ & 279.750 & $3,23 \%$ & 154 & $100,00 \%$ & 9.026 & $1,71 \%$ \\
\hline
\end{tabular}

\begin{tabular}{|c|c|c|c|c|c|c|c|c|c|}
\hline \multirow[b]{2}{*}{ Classe CNAE } & \multicolumn{5}{|c|}{ Emprego 2011} & \multicolumn{4}{|c|}{ Estabelecimentos 2011} \\
\hline & QL & $\begin{array}{l}\text { PFT } \\
\text { APL }\end{array}$ & $\begin{array}{c}\% \text { no total } \\
\text { de PFT } \\
\text { setorial do } \\
\text { APL }\end{array}$ & PFT BR & \begin{tabular}{|c|}
$\mathrm{PFT}$ \\
$\mathrm{APL}$ \\
$/ \mathrm{PFT}$ \\
$\mathrm{BR}$ \\
\end{tabular} & $\begin{array}{c}\text { ESTAB. } \\
\text { APL }\end{array}$ & $\begin{array}{c}\% \text { classe } \\
\text { nos ESTAB. } \\
\text { do total } \\
\text { setor APL }\end{array}$ & $\begin{array}{c}\text { ESTAB. } \\
\text { BR }\end{array}$ & $\begin{array}{c}\text { ESTAB, } \\
\text { APL / } \\
\text { ESTAB. } \\
\text { BR } \\
\end{array}$ \\
\hline $\begin{array}{l}\text { Fabricação } \\
\text { de laminados } \\
\text { planos e } \\
\text { tubulares } \\
\text { plástico }\end{array}$ & 0,98 & 116 & $0,88 \%$ & 18.898 & $0,61 \%$ & 5 & $2,03 \%$ & 430 & $1,16 \%$ \\
\hline $\begin{array}{l}\text { Fabricação de } \\
\text { embalagem } \\
\text { de plástico }\end{array}$ & 2,16 & 1582 & $12,04 \%$ & 116.903 & $1,35 \%$ & 29 & $11,79 \%$ & 3403 & $0,85 \%$ \\
\hline $\begin{array}{l}\text { Fabricação } \\
\text { de artefatos } \\
\text { diversos de } \\
\text { plástico }\end{array}$ & 8,77 & 11445 & $87,08 \%$ & 208.165 & $5,50 \%$ & 212 & $86,18 \%$ & 7.857 & $2,70 \%$ \\
\hline $\begin{array}{l}\text { Fabricação de } \\
\text { calçados de } \\
\text { plásticos }\end{array}$ & 0 & 0 & $0,00 \%$ & 57.301 & $0,00 \%$ & 0 & $0,00 \%$ & 653 & $0,00 \%$ \\
\hline Total setor & 5,23 & 13.143 & $100,00 \%$ & 401.267 & $3,28 \%$ & 246 & $100,00 \%$ & 12.343 & $1,99 \%$ \\
\hline Total & - & 290.200 & - & 46.310 .631 & $0,63 \%$ & 21.036 & - & 3.590 .616 & $0,59 \%$ \\
\hline
\end{tabular}

Nota: QL = (Emprego do setor i / Emprego microrregião j) / (Total do emprego do país no setor i / Emprego total do país). PFT $=$ Postos formais de trabalho.

Fonte: BRASIL, 2006 e 2011. 
As 154 empresas do APL pertencem às classes da Classificação Nacional de Atividades Econômicas (CNAE) fabricação de laminados planos e tubulares plásticos $(4,55 \%$ dos estabelecimentos), fabricação de embalagem de plástico $(16,88 \%)$ e fabricação de artefatos diversos de plásticos $(78,57 \%)$ (BRASIL, 2006). Destas, a amostra abrangeu 33 empresas, sendo 5 produtoras de embalagens e 28 de produtos diversos de plástico. As últimas foram subdivididas em dois segmentos principais, devido a sua intensa heterogeneidade em termos de produtos produzidos, conforme Tabela 2. A indisponibilidade de informações para identificar as empresas da classe de fabricação de laminados planos e tubulares plástico, apontadas pela RAIS (BRASIL, 2006), conduziu a exclusão dessa classe da pesquisa ${ }^{3}$.

Tabela 2 - População e Amostra das empresas por porte e atividade industrial do APL de transformados plásticos da região Norte do Estado de Santa Catarina, 2005

\begin{tabular}{|c|c|c|c|c|c|}
\hline \multirow[b]{3}{*}{$\begin{array}{c}\text { Porte } \\
\text { empresarial }^{\text {(a) }}\end{array}$} & \multicolumn{2}{|c|}{$\begin{array}{c}\text { Classe CNAE - Fabricação } \\
\text { de embalagens plásticas }\end{array}$} & \multicolumn{3}{|c|}{$\begin{array}{c}\text { Classe CNAE - Fabricação de artefatos diversos } \\
\text { de plástico }\end{array}$} \\
\hline & \multirow[b]{2}{*}{ População } & \multirow[b]{2}{*}{ Amostra $^{(b)}$} & \multirow[b]{2}{*}{ População ${ }^{\text {(c) }}$} & \multicolumn{2}{|c|}{\begin{tabular}{|c|} 
Amostra \\
\end{tabular}} \\
\hline & & & & $\begin{array}{l}\text { Subclasse CNAE 2529- } \\
\text { 1/03 - Fabricação de } \\
\text { artefatos diversos para } \\
\text { construção civil }\end{array}$ & $\begin{array}{c}\text { Fabricação } \\
\text { de artefatos } \\
\text { para outros } \\
\text { usos }{ }^{(d)} \\
\end{array}$ \\
\hline \multirow{2}{*}{ Micro } & 20 & 3 & 72 & 5 & 6 \\
\hline & $77 \%$ & $60 \%$ & $60 \%$ & $33 \%$ & $46 \%$ \\
\hline \multirow{2}{*}{ Pequena } & 3 & 1 & 31 & 4 & 6 \\
\hline & $12 \%$ & $20 \%$ & $26 \%$ & $27 \%$ & $46 \%$ \\
\hline \multirow{2}{*}{ Média } & 3 & 1 & 13 & 4 & 0 \\
\hline & $12 \%$ & $20 \%$ & $11 \%$ & $27 \%$ & $0 \%$ \\
\hline \multirow{2}{*}{ Grande } & 0 & 0 & 5 & 2 & 1 \\
\hline & $0 \%$ & $0 \%$ & $4 \%$ & $13 \%$ & $8 \%$ \\
\hline \multirow{2}{*}{ Total } & 26 & 5 & 121 & 15 & 13 \\
\hline & $100 \%$ & $100 \%$ & $100 \%$ & $100 \%$ & $100 \%$ \\
\hline
\end{tabular}

Notas:

(a) Número de funcionários por porte: Micro: até 19; Pequena: 20 a 99; Média: 100 a 499 e Grande: mais de 500. Classificação SEBRAE - Serviço Brasileiro de Apoio a Micro e Pequena Empresas.

(b) Tamanho mínimo da amostra por estratificação da atividade produtiva especificado no procedimento metodológico de Campos, Nicolau e Barbetta (2003).

3 A classe Fabricação de laminados planos e tubulares plástico foi a única cujo resultado do QL, para o ano de 20 I I, diferencia-se significativamente do verificado anteriormente, em 2005. No entanto, não prejudica a análise tendo em vista que, mesmo em 2005, não foram encontradas informações sobre a identidade das empresas pertencentes a essa classe. 
(c) Não existem dados disponíveis sobre número de estabelecimentos das subclasses CNAE.

(d) Engloba as demais subclasses - fabricação de artefatos de material plástico para uso pessoal e doméstico (subclasse CNAE 2529-1/01); fabricação de artefatos de material plástico para usos industriais - exclusive na indústria de construção civil (subclasse CNAE 2529-1/02) e fabricação de artefatos de material plástico para outros usos (subclasse CNAE 2529-1/99).

Fonte: BRASIL, 2006.

Cabe destacar que foi aplicado questionário nas empresas na forma presencial, visando obter respostas sobre as suas atividades cooperativas realizadas no período entre janeiro de 2004 e julho de 2006. A escolha das empresas dentro de cada um dos segmentos citados, foi efetuada de forma aleatória, com as informações coletadas entre 24.07.2006 e 31.08.2006.

\section{COOPERAÇÃO E ESTRUTURAS DE GOVERNANÇA}

A região Norte do estado figura-se entre os maiores pólos produtivos de plásticos transformados do Brasil, sendo que o APL conta com algumas das maiores empresas de transformados plásticos do país, além da existência de divisão de trabalho entre as distintas atividades desse setor, de uma rede de distribuição dos produtos produzidos pelas grandes empresas de construção civil e da presença de fornecedores de moldes e de distribuidores de resinas plásticas. Os principais produtos produzidos na região são peças técnicas e acessórios diversos para construção civil (mangueiras, tubos, conexões, registros, perfis e outros acessórios de PVC). Destaca-se um número significativo de MPEs que não possuem produto próprio e atuam no segmento de injeção ou extrusão por encomenda, caracterizadas pela baixa capacidade produtiva e cuja demanda está associada ao desempenho de empresas subcontratantes do mesmo e de outros setores industriais. Por sua vez, na fabricação de embalagens de plástico, têm-se as embalagens rígidas, principalmente, potes e frascos para produtos químicos, de limpeza e alimentos; e flexíveis, tais como sacos e sacolas plásticas, sacos para lixo e, em menor proporção, embalagens para indústria alimentícia.

Em relação ao ambiente institucional, destacam-se como instituições representativas o Sindicato da Indústria de Materiais Plásticos (SIMPESC, Associação de Joinville e Região da Pequena e Média Empresa (AJORPE- 
$\mathrm{ME}$ ), Associação Comercial e Industrial de Joinville (ACIJ) e a Associação Comercial e Industrial de Jaraguá do Sul (ACIJS). No campo educacional, tem-se a Sociedade Educacional de Santa Catarina (SOCIESC), que oferece cursos técnicos através da Escola Técnica Tupy, e superiores, através do Instituto Superior Tupy (IST), o Serviço Nacional de Aprendizagem Industrial (SENAI), a Universidade para o Desenvolvimento do Estado de Santa Cataria (UDESC), a Universidade da Região de Joinville (UNIVILLE) e o Centro Universitário de Jaraguá do Sul (UNERJ). No que diz respeito a serviços tecnológicos, o SENAI oferece assessoria técnica e tecnológica e certificação de processos e produtos, enquanto a SOCIESC é tida como uma instituição de excelência para as empresas locais. Por fim, tem-se o Serviço Brasileiro de Apoio a Micro e Pequena Empresas (SEBRAE) que, além de fomento, oferece diversos serviços de consultoria e cursos para capacitação empresarial voltados para as MPEs, assim como possui um núcleo setorial de plásticos.

\subsection{Características das Ações Conjuntas de Cooperação}

No estudo em pauta, $50 \%$ das micro (7 estabelecimentos), $72,7 \%$ das pequenas (8), 60\% das médias (3) e 100\% das grandes empresas (3) selecionadas declararam a realização de cooperação entre os anos de 2004 e 2006. Tal ocorrência sinaliza a necessidade de avaliar, em mais detalhes, as características dos processos de cooperação para compreender o estágio de desenvolvimento do arranjo em direção à construção de uma eficiência coletiva deliberada.

Os principais parceiros das atividades cooperativas refletem as formas de cooperação predominantes entre os agentes locais, considerando que tais atividades podem ser subdivididas em ações cooperativas verticais, horizontais e multilaterais. A cooperação vertical prevalece nas micro, pequenas e grandes empresas, as quais têm como parceiros mais importantes os fornecedores de insumos (equipamentos, matéria-prima e componentes) e os clientes (especialmente os clientes industriais). Mesmo com baixos índices de importância, os fornecedores e os clientes ocuparam a segunda posição dentre os parceiros apontados pelas médias empresas, conforme Tabela 3. 


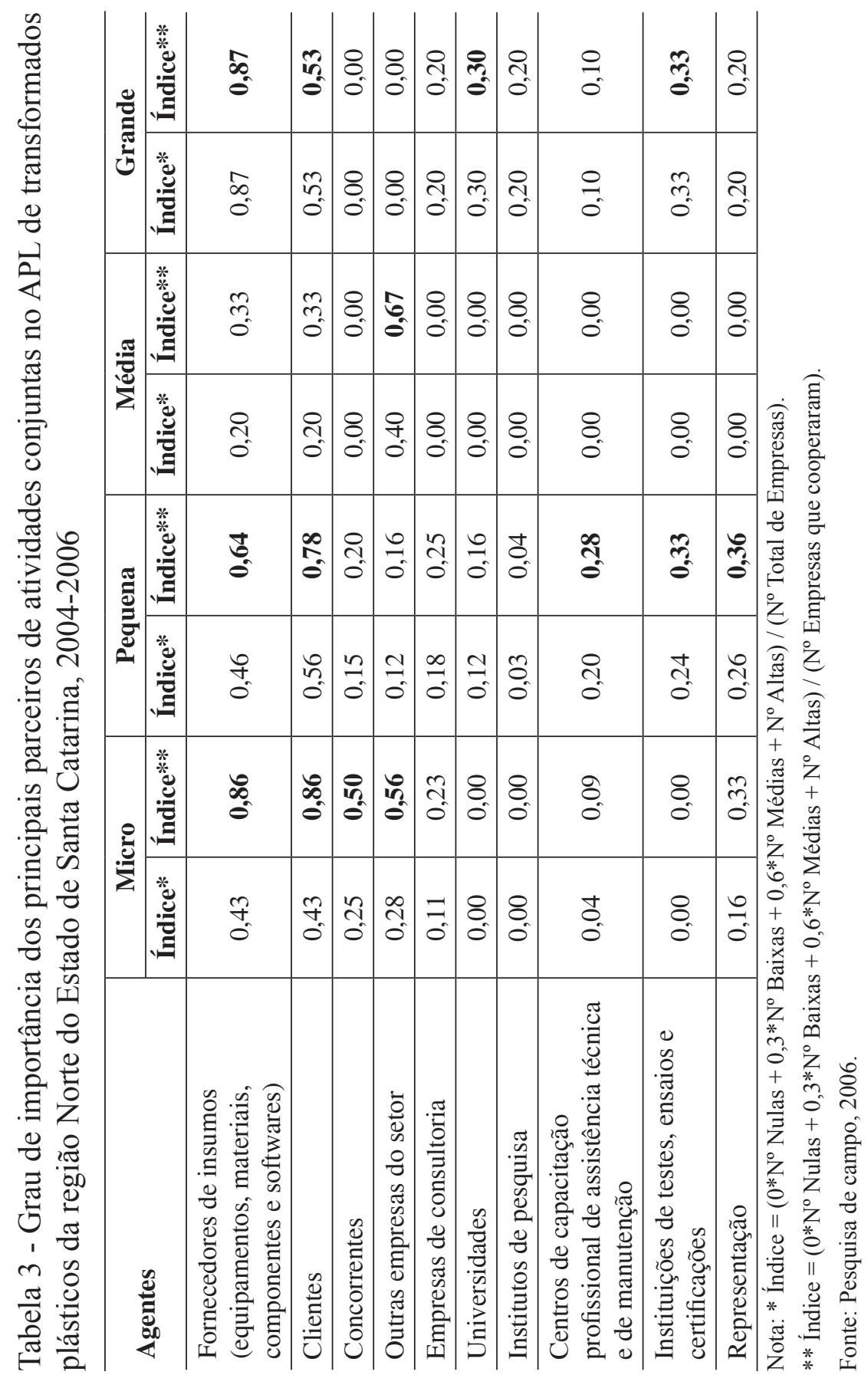


Cabe destacar que o alto índice atribuído em relação a ações conjuntas com clientes pelas microempresas está relacionado ao grande número dessas empresas que são subcontratadas por outras empresas do arranjo, como é o caso de algumas que atuam no segmento de artefatos plásticos para a construção civil e da grande maioria das que atuam no segmento de artefatos para outros usos (sob encomenda). Mesmo as empresas que não atuam exclusivamente sob encomenda são subcontratadas por outras empresas no arranjo, sendo os clientes os responsáveis pelo desenvolvimento dos moldes e produtos, bem como pela especificação dos padrões de qualidade. Por sua vez, o menor índice atribuído em relação aos clientes pelas grandes empresas, que foi de 0,53, deve-se, sobretudo, à baixa importância atribuída pelas empresas do segmento de artefatos de plástico para a construção civil, contrapondo-se à alta importância atribuída pela produtora de peças técnicas para indústria de transporte, pois, nesta última, são os clientes os responsáveis pelas especificações relevantes para o desenvolvimento de produto.

O nível de cooperação com fornecedores está vinculado com o regime tecnológico setorial vigente, tendo em vista que a mudança tecnológica ocorrida na indústria transformadora é gerada, predominantemente, a montante e a jusante. Nesse sentido, a cooperação revela-se tanto em termos de assistência técnica no processo produtivo para melhor utilização de matéria-prima e equipamentos, quanto no desenvolvimento de produtos através da fabricação conjunta de moldes plásticos. Este último assume particular importância no local devido às relações próximas e, muitas vezes, pessoais, entre os proprietários das empresas transformadoras de material plástico e das produtoras de moldes, visto que a região conta com um arranjo produtivo de moldes plásticos concentrado no município de Joinville.

Contrapondo-se ao quadro geral do arranjo, a cooperação horizontal revelou-se como a principal forma de cooperação para as médias empresas, que apontaram as empresas do mesmo setor (mas não concorrentes diretas) como os parceiros mais significativos para ações conjuntas, tais como as empresas fornecedoras de componentes ou que participam de etapas do processo produtivo, geralmente, MPEs subcontratadas do próprio arranjo. Outro aspecto que merece ênfase foi que somente as MPEs efetuaram ações conjuntas com concorrentes, com destaque para as microempresas, cujo índice de importância atingiu o valor de 0,50 , enquanto o das pequenas foi de 
0,20 . Vale esclarecer que as parcerias com os concorrentes diretos ocorrem de maneira informal ou extracontratual, mediante relações pessoais entre os proprietários dessas firmas. Os relatos apontaram que as formas de cooperação abrangem desde a utilização de capacidade produtiva do concorrente, diante da necessidade de cumprimento de prazos de entrega de produtos pelas empresas que atuam sob encomenda, assim como, na divisão dos custos fixos com instalações, através do compartilhamento de terreno alugado.

A cooperação multilateral não foi realizada pelas médias empresas, assim como apresentaram pouca importância para as empresas de demais portes. As microempresas praticamente não realizaram parcerias com as instituições pertencentes à infraestrutura de ensino e tecnologia. Por outro lado, ações conjuntas com institutos de pesquisa, universidades, centros de capacitação e instituições de testes, ensaios e certificações fizeram parte da conduta das pequenas e grandes empresas. As instituições de teste prevaleceram em ambos os portes empresariais $(0,33)$, seguido das universidades para as grandes $(0,30)$ e centros de capacitação tecnológica (SENAI) para as pequenas $(0,28)$. Tendo em vista a reconhecida importância dos serviços tecnológicos disponibilizados pela SOCIESC na região, o baixo índice atribuído à parceria com instituições de testes, ensaios e certificações revela que muitas empresas consideram que essa interação tem sido baseada somente em relações de mercado.

A cooperação multilateral no âmbito das organizações de classe e apoio também obteve baixos índices atribuídos. Nesse particular, as MPEs têm os agentes de representação, referindo-se à AJORPEME, como parceiros mais relevantes; enquanto as grandes empresas apontaram as entidades sindicais, sobretudo o SIMPESC. Os relatos mostraram que as empresas cujos proprietários atuam diretamente em tais organizações são as que, no geral, consideram essas entidades potenciais provedoras de atividades cooperativas entre os agentes econômicos e, então, relevantes para o desenvolvimento local, demonstrando uma ineficiência da interação das mesmas com as firmas locais.

No tocante as principais ações conjuntas realizadas entre os agentes inseridos no arranjo, destacam-se parcerias para o desenvolvimento de produtos e processos produtivos, que ocupou a primeira posição em todos os portes empresariais, exceto nas pequenas empresas, onde ocupou o segundo 
lugar conforme a Tabela 4. Sendo assim, as microempresas também realizaram cooperação baseada na elaboração conjunta de design e estilo dos produtos $(0,43)$, enquanto as pequenas obtiveram índices mais significativos na participação coletiva em feiras e na capacitação dos recursos humanos $(0,44$ e 0,43 , respectivamente).

Tabela 4 - Grau de importância das principais formas de cooperação no APL de materiais transformados de plástico da região Norte do estado de Santa Catarina, 2004-2006

\begin{tabular}{|c|c|c|c|c|c|c|c|c|}
\hline \multirow{2}{*}{ Descrição } & \multicolumn{2}{|c|}{ Micro } & \multicolumn{2}{|c|}{ Pequena } & \multicolumn{2}{|c|}{ Média } & \multicolumn{2}{|c|}{ Grande } \\
\hline & Índice* & Índice** & Índice* & Índice** & Índice* & Índice ${ }^{* *}$ & Índice* & Índice $* *$ \\
\hline $\begin{array}{l}\text { Compra de insumos e } \\
\text { equipamentos }\end{array}$ & 0,14 & 0,29 & 0,14 & 0,19 & 0,00 & 0,00 & 0,33 & 0,33 \\
\hline $\begin{array}{l}\text { Venda conjunta de } \\
\text { produtos }\end{array}$ & 0,07 & 0,14 & 0,14 & 0,19 & 0,20 & 0,33 & 0,10 & 0,10 \\
\hline $\begin{array}{l}\text { Desenvolvimento de } \\
\text { Produtos e processos }\end{array}$ & 0,26 & 0,51 & 0,32 & 0,44 & 0,52 & 0,87 & 0,67 & 0,67 \\
\hline $\begin{array}{l}\text { Design e estilo de } \\
\text { Produtos }\end{array}$ & 0,21 & 0,43 & 0,19 & 0,26 & 0,12 & 0,20 & 0,33 & 0,33 \\
\hline $\begin{array}{l}\text { Capacitação de } \\
\text { Recursos Humanos }\end{array}$ & 0,11 & 0,23 & 0,31 & 0,43 & 0,00 & 0,00 & 0,40 & 0,40 \\
\hline $\begin{array}{l}\text { Obtenção de } \\
\text { financiamento }\end{array}$ & 0,00 & 0,00 & 0,05 & 0,08 & 0,00 & 0,00 & 0,53 & 0,53 \\
\hline Reivindicações & 0,06 & 0,13 & 0,21 & 0,29 & 0,00 & 0,00 & 0,33 & 0,33 \\
\hline $\begin{array}{l}\text { Participação conjunta } \\
\text { em feiras, etc }\end{array}$ & 0,14 & 0,29 & 0,35 & 0,48 & 0,20 & 0,33 & 0,30 & 0,30 \\
\hline
\end{tabular}

Nota: $*$ Índice $=\left(0 * \mathrm{~N}^{\mathrm{o}}\right.$ Nulas $+0,3 * \mathrm{~N}^{\circ}$ Baixas $+0,6 * \mathrm{~N}^{\circ}$ Médias $+\mathrm{N}^{\circ}$ Altas $) /\left(\mathrm{N}^{\circ}\right.$ Total de Empresas $)$ $* *$ Índice $=\left(0^{*} \mathrm{~N}^{\circ}\right.$ Nulas $+0,3 * \mathrm{~N}^{\circ}$ Baixas $+0,6^{*} \mathrm{~N}^{\circ}$ Médias $+\mathrm{N}^{\circ}$ Altas $) /\left(\mathrm{N}^{\circ}\right.$ Empresas que cooperaram $)$ Fonte: Pesquisa de campo, 2006.

Por sua vez, as médias empresas também atribuíram segundo lugar para a venda conjunta de produtos e participação conjunta em feiras (ambos os índices iguais a 0,33). Por fim, as grandes empresas atribuíram a segunda e terceira posições para a cooperação na obtenção de financiamento $(0,53)$ e na capacitação de recursos humanos $(0,40)$, diferenciando-se das demais em virtude da maior importância para a compra conjunta de insumos e equipamentos. Esse resultado deve-se a um caso em particular de uma empresa 
de grande porte que importa matéria-prima, a preços mais baixos e prazos mais longos de financiamento que os encontrados no mercado nacional e, em troca, fornece tecnologia através do desenvolvimento de produto para a empresa com a qual faz parceria.

No que concerne aos resultados das ações conjuntas, as parcerias das microempresas com outros agentes resultaram, em primeiro lugar, em melhoria dos processos produtivos, que alcançou índice de importância de 0,74 , conforme a Tabela 5. Figuraram entre os índices 0,60 e 0,69 como resultados positivos, os seguintes itens: melhoria na qualidade de produtos decorrente a parcerias com fornecedores, surgimento de novas oportunidades de negócios, desenvolvimento de novos produtos mediante ações conjuntas com clientes, bem como a melhoria nas condições de fornecimento dos produtos, mais especificamente, referindo-se à redução dos prazos de entrega. Nas pequenas empresas destacaram-se resultados em termos de melhor capacitação dos recursos humanos (fruto de parcerias formais com centros de capacitação profissional), assim como do surgimento de novas oportunidades de negócios e da melhoria de produtos e processos produtivos, cujos índices de importância atribuídos encontram-se entre 0,44 e 0,53.

Tabela 5 - Resultados das ações conjuntas no APL de materiais transformados de plástico da região Norte do estado de Santa Catarina, 2004-2006

\begin{tabular}{l|c|c|c|c|c|c|c|c}
\hline \multirow{2}{*}{ Descrição } & \multicolumn{2}{|c|}{ Micro } & \multicolumn{2}{c|}{ Pequena } & \multicolumn{2}{c|}{ Média } & \multicolumn{2}{c}{ Grande } \\
\cline { 2 - 9 } & Índice $^{*}$ & Índice** & Índice* & Índice** & Índice* & Índice** & Índice* & Índice** \\
\hline $\begin{array}{l}\text { Melhoria na qualida- } \\
\text { de dos produtos }\end{array}$ & 0,34 & 0,69 & 0,32 & 0,44 & 0,20 & 0,33 & 0,53 & 0,53 \\
\hline $\begin{array}{l}\text { Desenvolvimento de } \\
\text { novos produtos }\end{array}$ & 0,32 & 0,64 & 0,25 & 0,34 & 0,60 & 1,00 & 0,53 & 0,53 \\
\hline $\begin{array}{l}\text { Melhoria nos proces- } \\
\text { sos produtivos }\end{array}$ & 0,37 & 0,74 & 0,31 & 0,43 & 0,24 & 0,40 & 0,87 & 0,87 \\
\hline $\begin{array}{l}\text { Melhoria nas condi- } \\
\text { ços de fornecimento } \\
\text { dos produtos }\end{array}$ & 0,30 & 0,60 & 0,28 & 0,39 & 0,20 & 0,33 & 0,30 & 0,30 \\
\hline $\begin{array}{l}\text { Melhor capacitação } \\
\text { de recursos humanos }\end{array}$ & 0,19 & 0,37 & 0,37 & 0,51 & 0,06 & 0,10 & 0,43 & 0,43 \\
\hline
\end{tabular}


Relações interativas e estruturas de governança no arranjo produtivo local de transformados plásticos de Santa Catarina

\begin{tabular}{|c|c|c|c|c|c|c|c|c|}
\hline \multirow{2}{*}{ Descrição } & \multicolumn{2}{|c|}{ Micro } & \multicolumn{2}{|c|}{ Pequena } & \multicolumn{2}{|c|}{ Média } & \multicolumn{2}{|c|}{ Grande } \\
\hline & Índice* & Índice** & Índice* & Índice*** & Índice* & Índice** & Índice* & Índice** \\
\hline $\begin{array}{l}\text { Melhoria nas condi- } \\
\text { ções de comerciali- } \\
\text { zação }\end{array}$ & 0,16 & 0,31 & 0,19 & 0,26 & 0,40 & 0,67 & 0,53 & 0,53 \\
\hline $\begin{array}{l}\text { Introdução de inova- } \\
\text { ções organizacionais }\end{array}$ & 0,14 & 0,27 & 0,25 & 0,35 & 0,00 & 0,00 & 0,20 & 0,20 \\
\hline $\begin{array}{l}\text { Novas oportunidades } \\
\text { de negócios }\end{array}$ & 0,34 & 0,69 & 0,34 & 0,46 & 0,40 & 0,67 & 0,63 & 0,63 \\
\hline $\begin{array}{l}\text { Promoção de nome/ } \\
\text { marca da empresa no } \\
\text { mercado nacional }\end{array}$ & 0,25 & 0,50 & 0,19 & 0,26 & 0,32 & 0,53 & 0,53 & 0,53 \\
\hline $\begin{array}{l}\text { Maior inserção da } \\
\text { empresa no mercado } \\
\text { externo }\end{array}$ & 0,00 & 0,00 & 0,00 & 0,00 & 0,00 & 0,00 & 0,20 & 0,20 \\
\hline
\end{tabular}

Notas: $*$ Índice $=\left(0 * \mathrm{~N}^{\circ}\right.$ Nulas $+0,3 * \mathrm{~N}^{\circ}$ Baixas $+0,6^{*} \mathrm{~N}^{\circ}$ Médias $+\mathrm{N}^{\circ}$ Altas $) /\left(\mathrm{N}^{\circ}\right.$ Total de Empresas $)$ $* *$ Índice $=\left(0^{*} \mathrm{~N}^{\circ}\right.$ Nulas $+0,3 * \mathrm{~N}^{\circ}$ Baixas $+0,6^{*} \mathrm{~N}^{\circ}$ Médias $+\mathrm{N}^{\circ}$ Altas $) /\left(\mathrm{N}^{\circ}\right.$ Empresas que cooperaram $)$ Fonte: Pesquisa de campo, 2006.

As atividades cooperativas realizadas pelas médias empresas foram eficazes para o desenvolvimento de novos produtos em 100\% das empresas, como também para o surgimento de novas oportunidades de negócios (índice igual a 0,67$)$, para a ocorrência de melhorias nas condições de comercialização $(0,67)$ e para promover o nome ou a marca da empresa no mercado nacional $(0,53)$. No que tange às grandes empresas, o principal resultado alcançado foi relativo à melhoria nos processos produtivos $(0,87)$, seguido de novas oportunidades de negócios $(0,63)$. Cabe salientar que os índices de importância revelaram que os resultados das ações cooperativas foram significativamente superiores para as médias e grandes empresas.

O Quadro 1 resume as características das atividades cooperativas realizadas no APL, demonstrando a incipiência das relações interativas, dada a relevância das ações conjuntas para o desenvolvimento de produtos devido às relações de subcontratação e a não participação de micro e pequenas empresas em acões que poderiam resultar em upgrade de vantagens competitivas, tais como promoção da marca e melhoria nas condições de comercialização. 
Quadro 1 - Características das atividades cooperativas realizadas no APL de materiais transformados de plástico da região Norte do estado de Santa Catarina

\begin{tabular}{|c|c|c|c|c|}
\hline & Micro & Pequena & Média & Grande \\
\hline $\begin{array}{l}\text { Intensidade e } \\
\text { formalização } \\
\text { das interações }\end{array}$ & $\begin{array}{c}\text { Baixa }(50 \%) \\
\text { Informais }\end{array}$ & $\begin{array}{l}\text { Média }(72,7 \%) \\
\text { Informais }\end{array}$ & $\begin{array}{l}\text { Média }(60 \%) \\
\text { Informais }\end{array}$ & $\begin{array}{c}\text { Alta }(100 \%) \\
\text { Informais e formais }\end{array}$ \\
\hline $\begin{array}{l}\text { Principais } \\
\text { parceiros }\end{array}$ & $\begin{array}{c}\text { Fornecedores, } \\
\text { clientes e, em menor } \\
\text { grau, empresas do } \\
\text { mesmo setor e con- } \\
\text { correntes }\end{array}$ & $\begin{array}{l}\text { Fornecedores e } \\
\text { clientes }\end{array}$ & $\begin{array}{c}\text { Empresas do } \\
\text { mesmo setor, mas } \\
\text { não concorrentes } \\
\text { diretos }\end{array}$ & $\begin{array}{l}\text { Fornecedores e } \\
\text { empresas parte do } \\
\text { grupo e, em menor } \\
\text { grau, os clientes } \\
\text { (caso do segmen- } \\
\text { to de artefatos } \\
\text { de plásticos para } \\
\text { outros usos) }\end{array}$ \\
\hline $\begin{array}{l}\text { Formas de } \\
\text { cooperação }\end{array}$ & $\begin{array}{l}\text { Desenvolvimento de } \\
\text { produtos e proces- } \\
\text { sos e mudanças no } \\
\text { design e estilo de } \\
\text { produtos }\end{array}$ & $\begin{array}{c}\text { Desenvolvimento } \\
\text { de Produtos e pro- } \\
\text { cessos e, em menor } \\
\text { grau capacitação de } \\
\text { recursos humanos } \\
\text { e participação con- } \\
\text { junta em férias }\end{array}$ & $\begin{array}{l}\text { Desenvolvimen- } \\
\text { to de Produtos e } \\
\text { processos }\end{array}$ & $\begin{array}{l}\text { Desenvolvimento } \\
\text { de Produtos e pro- } \\
\text { cessos e, em menor } \\
\text { grau para obtenção } \\
\text { de financiamento } \\
\text { e capacitação de } \\
\text { recursos humanos }\end{array}$ \\
\hline $\begin{array}{l}\text { Resultados da } \\
\text { cooperação }\end{array}$ & $\begin{array}{c}\text { Desenvolvimento } \\
\text { de novos produtos } \\
\text { e melhoria na quali- } \\
\text { dade dos produtos e } \\
\text { processos produtivos } \\
\text { Novas oportunidades } \\
\text { de negócios }\end{array}$ & $\begin{array}{c}\text { Desenvolvimento } \\
\text { de novos produtos, } \\
\text { Melhor capacita- } \\
\text { ção de recursos } \\
\text { humanos } \\
\text { Novas oportunida- } \\
\text { des de negócios }\end{array}$ & $\begin{array}{c}\text { Desenvolvimento } \\
\text { de novos produtos } \\
\text { Novas oportunida- } \\
\text { des de negócios, } \\
\text { Melhoria nas con- } \\
\text { dições de comer- } \\
\text { cialização }\end{array}$ & $\begin{array}{l}\text { Melhoria nos pro- } \\
\text { cessos produtivos e } \\
\text { novas oportunida- } \\
\text { des de negócios }\end{array}$ \\
\hline
\end{tabular}

Fonte: Pesquisa de campo, 2006.

Assim como no que tange às práticas inovativas, as ações conjuntas com outros agentes são mais frequentemente incorporadas nas estratégias das médias e grandes empresas, em comparação com as MPEs, que voltam-se prioritariamente para as resoluções de problemas no âmbito da produção e comercialização. Porém, um dos aspectos positivos concerne na observação de que, embora com menor participação relativa, as microempresas e, em menor grau, as pequenas que declararam praticar atividades cooperativas indicaram índices consideráveis para uma diversidade de parceiros e ações conjuntas. Tal resultado revela que, entre as que praticam essas atividades, 
houve uma incorporação das ações coletivas nas suas estratégias empresariais, devido às próprias necessidades das mencionadas empresas para a superação de obstáculos diversos

\subsection{Estruturas de Governança}

Dentre os principais agentes que exercem influência sobre a organização produtiva do APL, tem-se: as empresas inseridas, as organizações formais de representação e as organizações pertencentes à infraestrutura de apoio, de ensino e tecnológica. Assim, tem-se que os atores internos são os responsáveis pela coordenação do arranjo, mais especificamente, as grandes e médias por meio de relações de subcontratação com MPEs.

A caracterização do desenho institucional abrange o papel das organizações formais e das regras e rotinas vinculadas ao contexto cultural e histórico do local. Há presença de organizações com função de mediar as relações de poder entre os agentes econômicos e fornecer informações para a construção de capacitação tecnológica - SIMPESC, da ACIJ, a ACIJS e a AJORPEME - ainda que as empresas tenham atribuído baixos índices de importância tanto quanto ao papel dessas entidades nas parcerias de atividades cooperativas, como em termos de contribuição no fornecimento de informações e de realização de ações que poderiam vir a corroborar para o desenvolvimento do arranjo. Nesse contexto, destacou-se a influência da AJORPEME, estimulando a interação das microempresas associadas ao núcleo setorial de plásticos, onde os proprietários confabulam ações conjuntas que podem a vir a corroborar com o aumento da competitividade das mesmas.

No âmbito da governança pública, os relatos não sinalizaram a existência de ações do setor púbico que sejam relevantes, internas ou externas ao arranjo. Além de não existir políticas específicas voltadas para o setor ou para o arranjo, as expectativas das empresas em relação aos órgãos competentes restringem-se à captação de crédito, visto que vislumbram o setor público como um articulador de políticas setoriais mais diretas. Da mesma forma, as entidades formais presentes assumem importância apenas para as empresas cujos proprietários são membros delas, enquanto as outras consideram-se a margem dos processos decisórios, indicando uma insegu- 
rança por parte dos agentes em termos de confiança nas instituições locais quanto à definição de objetivos comuns. Contudo, não se pode desmerecer o papel dessas entidades para a organização de eventos essenciais para que as empresas, por um lado, aumentem sua visibilidade em nível nacional e, por outro, contribuam com a disseminação de informações tecnológicas e mercadológicas. A INTERPLAST - Feira e Congresso Nacional de Integração de Tecnologia do Plástico, organizada pelo SIMPESC, é um bom exemplo dessa atuação.

Por outro lado, os condicionantes históricos e culturais, que favoreceram a formação de um pólo industrial na região - o APL emergiu tendo como centro dinâmico as empresas pioneiras atuantes no segmento de construção civil - continuam contribuindo para a sua trajetória de desenvolvimento. A atmosfera industrial da região, o alto padrão de qualidade de vida e as oportunidades de negócios geram um ambiente favorável aos investimentos, em virtude das externalidades multissetoriais e específicas à indústria de produtos transformados de plástico. Averiguou-se que não somente muitas empresas surgiram ao beneficiar-se da proximidade com as firmas líderes através de oportunidades de negócios via relações de subcontratação (primeiramente as grandes empresas e, posteriormente, as médias que consolidaram-se no mercado nos anos 90), como também muitos proprietários das novas firmas são antigos empregados de empresas do próprio arranjo. Assim, a fraca abrangência das entidades formais é compensada, em certa medida, por relações pessoais de confiança entre os empresários locais, que acabam por instituir atividades cooperativas informais.

No que diz respeito à infraestrutura educacional e tecnológica, o arranjo conta com uma desenvolvida infraestrutura de ensino, pesquisa e apoio tecnológico. No campo educacional, destacam-se os cursos técnicos especializados oferecidos pela Escola Técnica Tupy (SOCIESC) e pelo SENAI, que oferecem o curso de Gestão de Processos Industriais e Ferramentaria de Moldes. O SENAI também oferta o curso de ensino superior Gestão da Produção e Serviços Industriais, enquanto a UDESC, a UNIVILLE e o UNERJ oferecem graduação em Engenharia Mecânica, Engenharia de Produção e Engenharia de Plásticos, entre outros. Além disso, o SENAI e a SOCIESC disponibilizam serviços de assessoria técnica e tecnológica, bem como serviços de certificação de processo e produtos. Conta-se, ain- 
da, com o SEBRAE que oferece diversos serviços de consultoria e cursos para a capacitação empresarial voltados para MPEs, assim como possui um núcleo setorial de plásticos.

Essas instituições teriam como objetivo "organizar e coordenar os fluxos de informações e conhecimento relevantes para o processo de capacitação produtiva e inovativa de atores locais" (VARGAS, 2002, p. 13). No entanto, tais organizações exercem um baixo impacto para intensificar os fluxos de informações e estimular o aprendizado interativo, como também não foram apontadas dentre os principais parceiros para atividades cooperativas. A maior parte das pesquisas necessárias para inovações é realizada pelas firmas líderes e não pelas universidades, pois os cursos de engenharia, em suas áreas de especialização, que poderiam corroborar nessa função, não desenvolvem pesquisa em tecnologias críticas para a capacitação tecnológica das firmas, retratando a fraca interação universidade-empresa na região.

Na mesma situação encontram-se os cursos profissionalizantes existentes na área, que não são a principal fonte de informação para a capacitação dos recursos humanos, devido a importância do conhecimento tácito e o grande contingente de trabalhadores que completaram somente o ensino médio, especialmente nas MPEs. Nessas empresas prevalece a capacitação através de treinamento nas próprias firmas que, no geral, possuem um técnico em plásticos, responsável pelo gerenciamento da produção e treinamento dos demais funcionários. Diante desse quadro, pode-se dizer que imperam interações restritas a relações de mercado, via utilização contratual dos serviços oferecidos pelas organizações.

Por outro lado, as instituições referenciadas foram apontadas dentre as principais vantagens locacionais, revelando que as mesmas são extremamente importantes, senão para todo o arranjo, ao menos para algumas firmas. Dentre as instituições, a SOCIESC foi assinalada como a de maior relevância, sobretudo para as MPEs, tanto em razão dos serviços tecnológicos oferecidos (infraestrutura laboratorial para análises de matéria-prima, manutenção para maquinário e certificação de processos e produtos), como em relação às consultorias direcionadas para a inovação tecnológica e programas de apoio à indústria.

Essas análises possibilitam estabelecer a estrutura de governança do arranjo dentro das tipologias sugeridas por Storper e Harrison (1994), 
uma vez que a constatação de fluxos de informações e atividades de cooperação indica que as relações entre os atores do APL extrapolam as relações puramente de mercado. Nesse particular, registrou-se que as informações tecnológicas são geradas por esforços das médias e grandes empresas locais para o desenvolvimento de produto e processo, que acabam beneficiando as MPEs a partir de estratégias imitativas. Em complemento, tem-se um significativo percentual de empresas que realizaram atividades cooperativas horizontais, mais especificamente, entre empresas subcontratantes e subcontratadas do arranjo. Esse contexto evidencia que as relações de subcontratação se sobressaem, com clara liderança das empresas subcontratantes sobre as demais empresas. O Quadro 2 expõe as estruturas de governança que ocorrem no arranjo produtivo de produtos transformados de materiais plásticos em estudo, conforme a tipologia de Storper e Harrison (1994).

Considerando as relações de hierarquia e liderança, a governança local está mais próxima da estrutura core-ring with lead firm, que reflete situações em que as empresas líderes são independentes dos seus fornecedores locais, ao mesmo tempo em que "condicionam a existência de certo número dos seus parceiros” (STORPER e HARRISON, 1994, p.177). Nesse caso, as empresas fornecedoras são as MPEs transformadoras de material plástico com as quais as grandes e médias (líderes) possuem relações de subcontratação horizontais. A hierarquia é evidente, pois as firmas líderes não dependem das menores para a continuidade de suas atividades produtivas - poderiam internalizar a produção dos componentes atualmente fornecidos pelas MPEs ou, ainda, substituir os fornecedores locais por empresas localizadas fora do arranjo - enquanto a maioria das empresas subcontratadas não teria a oportunidade de sobreviver no mercado caso não existisse uma concentração setorial de empresas.

A evolução histórica do arranjo mostra que muitos dos produtos que são fornecidos atualmente já fizeram parte das atividades produtivas dessas empresas. Sendo assim, a intensificação das relações de subcontratação faz parte da tendência de desverticalização da produção, pelas médias e grandes empresas, com intuito de especialização das suas atividades produtivas em produtos de maior valor agregado. Essa é a estrutura de governança estabelecida entre as médias e grandes empresas do segmento de artefatos 
plásticos para a construção civil e a maior parte das MPEs subcontratadas desse segmento e do segmento de artefatos plásticos para outros usos, sobretudo aquelas que atuam exclusivamente sob encomenda. Vale ressaltar que as firmas líderes do segmento de construção civil têm a marca como principal ativo específico de valor, que se tornou sinônimo de qualidade para os consumidores finais. Nessa situação, faz-se necessário que as mesmas não somente forneçam os moldes, como especifiquem o padrão de qualidade, muitas vezes fornecendo matéria-prima e bens de capital fora de utilização para as empresas subcontratadas.

Quadro 2 - Estruturas de governança do APL de produtos transformados de materiais plásticos da região Norte do estado de Santa Catarina

\begin{tabular}{|l|c|c|}
\hline $\begin{array}{l}\text { Estruturas de } \\
\text { governança }\end{array}$ & Segmento principal & Características e principais agentes \\
\hline $\begin{array}{l}\text { Core ring with a } \\
\text { lead firm }\end{array}$ & $\begin{array}{c}\text { Fabricação de artefatos plásti- } \\
\text { cos para construção civil }\end{array}$ & $\begin{array}{c}\text { Empresas líderes são as médias e grandes } \\
\text { empresas do segmento de artefatos plásticos } \\
\text { para construção civil, que possuem relações de } \\
\text { subcontratação horizontais com as MPEs locais }\end{array}$ \\
\hline $\begin{array}{l}\text { Core ring with } \\
\text { a coordinating } \\
\text { firm }\end{array}$ & $\begin{array}{l}\text { Fabricação de artefatos plásti- } \\
\text { cos para construção civil e Fa- } \\
\text { bricação de artefatos plásticos } \\
\text { para outros usos }\end{array}$ & $\begin{array}{l}\text { Entre algumas MPEs, cuja hierarquia é menor, } \\
\text { em virtude da dificuldade em que se as empre- } \\
\text { sas coordenadoras - pequenas subcontratantes } \\
\text { de micro - tem para operarem sem seus respec- } \\
\text { tivos fornecedores locais }\end{array}$ \\
\hline All ring no core & $\begin{array}{l}\text { Fabricação de artefatos plásti- } \\
\text { cos para construção civil; Fa- } \\
\text { bricação de artefatos plásticos } \\
\text { para outros usos e Fabricação } \\
\text { de embalagens plásticas }\end{array}$ & $\begin{array}{c}\text { Coordenação realizada pelo Núcleo Setorial de } \\
\text { Plásticos da AJORPEME, algumas MPEs da } \\
\text { região interagem de forma cooperativa e sem } \\
\text { presença de hierarquia }\end{array}$ \\
\hline $\begin{array}{l}\text { Governança de } \\
\text { mercado }\end{array}$ & $\begin{array}{l}\text { Fabricação de artefatos plásti- } \\
\text { cos para outros usos e Fabrica- } \\
\text { ção de embalagens plásticas }\end{array}$ & $\begin{array}{c}\text { MPEs que possuem produtos próprios desti- } \\
\text { nados para consumidores finais,bem como a } \\
\text { grande empresas produtora de peça técnica e } \\
\text { das empresas de embalagens plásticas. }\end{array}$ \\
\hline
\end{tabular}

Fonte: Pesquisa de campo, 2006.

Porém, diversas empresas não podem ser agrupadas na taxonomia exposta. Dentre algumas destas, pode-se dizer que prevalece uma estrutura próxima a core-ring with coordinating firm, que se caracteriza por uma estrutura de governança com algum grau de hierarquia e com assimetria 
entre agentes, mas a influência sistêmica das firmas líderes é limitada, por não determinar, necessariamente, a sobrevivência das outras empresas. Assim, as empresas coordenadoras seriam as pequenas subcontratantes das microempresas. A hierarquia, portanto, é mais fraca: por um lado, tem-se que as pequenas empresas não podem facilmente internalizar a produção dos bens fornecidos (a tecnologia é simples, contudo, não possuem bens de capital apropriados) e, por outro, a substituição dos fornecedores locais por aqueles localizados fora do arranjo aumentaria significativamente os custos de transporte.

Ademais, há indícios de que algumas MPEs que não se enquadram em nenhuma dessas situações até o momento explicitadas, quer de líderes sobre outras, quer de subordinadas das mesmas, porque tais empresas não possuem qualquer tipo de relações de subcontratação no local. É o caso das MPEs que possuem produtos próprios destinados para consumidores finais, da grande empresa produtora de peças técnicas (que tem relações contratuais com empresas fora do arranjo) e das empresas de embalagens plásticas (especialmente produtoras de sacos e sacolas), regidas, no local, por governança de mercado.

Por sua vez, dentre algumas micro empresas da região, averiguaram-se indícios de relações coordenadas sem hierarquia entre as mesmas, próxima da taxonomia denominada all ring no core. Nesse caso, a coordenação é realizada pela AJORPEME, onde se encontram, entre as associadas, empresas pertencentes aos três segmentos produtivos expostos. Sendo assim, registra-se a grande importância da existência do núcleo setorial de plásticos e da sua iniciativa para a intensificação da cooperação entre os agentes participantes. Porém, o número de empresas abrangidas por essas iniciativas é pouco significativo, ainda que tal constatação indique a possibilidade de expansão desses ganhos externos, via condutas ativas de cooperação, com tendência para o alcance da eficiência coletiva no futuro.

\section{CONCLUSÕES}

Embora a maioria das empresas inseridas no APL de transformados de plástico da região Norte do Estado catarinense tenham realizado algum tipo de cooperação no período observado, as características desse 
processo sugerem necessidade de mudança nas estratégias empresariais para a construção de vantagens competitivas dinâmicas. Averiguou-se o predomínio das formas verticais de cooperação, mediante ações conjuntas com fornecedores de matéria-prima, bens de capital e clientes, enquanto as atividades cooperativas horizontais (com concorrentes) e multilaterais (entidades representativas e instituições de ensino e tecnologia) mostram-se incipientes. Dentre os principais resultados das ações conjuntas tem-se o desenvolvimento de novos produtos, a melhoria dos processos produtivos, aumento da qualidade de produtos e novas oportunidades de negócios.

Foi possível identificar algumas estruturas de governança predominantes, conforme a taxonomia de Storper e Harrison (1991). Sobressai-se a estrutura core-ring with lead firm, cujas empresas líderes são as médias e grandes empresas do segmento de artefatos plásticos para a construção civil, que possuem relações de subcontratação horizontais com as MPEs locais. Em segundo lugar, há indícios de que entre algumas MPEs prevalece uma estrutura próxima a core-ring with coordinating firm, cuja hierarquia é menor, em virtude da dificuldade que as empresas coordenadoras - pequenas - têm para operarem sem seus respectivos fornecedores locais. Por outro lado, através da coordenação realizada pelo Núcleo Setorial de Plásticos da AJORPEME, algumas MPEs interagem de forma cooperativa e sem a presença de hierarquia, que se caracteriza pela taxonomia denominada all ring no core. Finalmente, observaram-se situações caracterizadas pela inexistência de uma estrutura de governança definida, em particular, no caso das MPEs que possuem produtos próprios destinados para consumidores finais, da grande empresa produtora de peças técnicas e das empresas de embalagens plásticas.

Nesse aspecto, verifica-se um alto grau de territorialidade do APL, em virtude da existência de infraestrutura física e tecnológica; proximidade com clientes, disponibilidade de mão-de-obra qualificada, intensa divisão de trabalho intrassetorial e transbordamento do conhecimento tácito no local. Porém, a fraca interação entre o desenvolvido arcabouço institucional local e as empresas inseridas no arranjo colocou em evidência a necessidade de políticas específicas que intensifiquem os fluxos de informações relevantes para a inovação e que estimulem as ações cooperativas entre os agentes. 
INTERACTIVE RELATIONSHIPS AND GOVERNANCE STRUCTURES IN THE LOCAL PRODUCTIVE ARRANGEMENT OF PROCESSED PLASTICS OF SANTA CATARINA

\begin{abstract}
The aim of this article is to verify how the actions developed by the local productive arrangement agents of processed plastics in the north of Santa Catarina, Brazil, are contributing to build and support dynamic competitive advantages. Indeed, from literature about cooperation and governance structures in local productive arrangements, the interactive relationships of the industry in the arrangement are been analyzed. The results obtained from field research, composed by 33 firms of plastic packages and various artifacts made of plastic segment indicate that, between the interactive relationships of the agents, the vertical cooperation ways and the subcontracting relationships stand out, resulting in several ways of governance, showing that the firms benefits themselves mainly of passive locational advantages.
\end{abstract}

Keywords: Local Productive Arrangement, Governance, Plastic Products Industry.

JEL Classification: L, L2, L20, L23

\title{
6. REFERÊNCIAS
}

BRITTO, J. N de P.; ALBUQUERQUE, E. M. Aglomerações industriais e desenvolvimento local na região Sul: análise exploratória. In: ENCONTRO DE ECONOMIA DA REGIÃO SUL - ANPEC/SUL, 2002. Florianópolis. Anais. Florianópolis, ANPEC/SUL, 2002. CD ROM.

CAMPOS, R. R. Ampliando espaços de aprendizagem: um foco para políticas de estímulos aos arranjos produtivos locais. In: COLÓQUIO INTERNACIONAL DE DESENVOLVIMENTO LOCAL, Campo Grande, 2003. Anais. Campo Grande, 2003. CD ROM. 
CAMPOS, R. R.; NICOLAU, J. A.; BARBETTA, P. A. A. Aspectos Metodológicos para Pesquisa em Micro e Pequenas Empresas em Arranjos Produtos Locais. In: CAMPOS, R. R. (Coord). Nota Técnica 2 do Projeto de pesquisa "Micro e pequena empresa em arranjos produtivos locais no Brasil. Nota Técnica 2 (Versão Preliminar). Florianópolis: Universidade Federal de Santa Catarina/SEBRAE, 2002.

CASSIOLATO, J. E.; LASTRES, H. M. M. O enfoque em sistemas produtivos e inovativos locais. In: FISCHER,T. (Org.) Gestão do desenvolvimento e poderes locais: marcos teóricos e avaliação. Salvador/ BA: Casa da Qualidade, 2002.

CASSIOLATO, J. E.; LASTRES, H. M. M. O foco em arranjos produtivos e inovativos locais de MPEs. In: LASTRES, H. M. M; CASSIOLATO, J. E. \& MACIEL, M. L. (Org.). Pequena Empresa: cooperação e desenvolvimento local. Rio de Janeiro: Reluma Dumará Editora, 2003.

GEREFFI, G. International trade and industrial upgrading in the apparel commodity chain. Journal of International Economics, v. b, p. 37-70, 2009.

HUMPRHEY, J.; SCHMITZ, H. Governance global value chain. IDS Bulletin,. v. 32, n. 3. Brighton, UK, 2001.

BRASIL. Ministério do Trabalho e Emprego. Relação Anual de Informações Sociais - RAIS/MTE. Base de Dados. 2006. 2011. CD ROM.

SANTOS, G. A. G. dos et al. Aglomerações, arranjos produtivos locais e vantagens competitivas locacionais. In: BNDES (Org.). Arranjos produtivos locais e desenvolvimento: versão preliminar. Seminário Arranjos Produtivos Locais como Instrumento de Desenvolvimento, 26 e 27 de outubro de 2004. Cap. 3 - p. 17 - 47. Rio de Janeiro: BNDES, 2004a. Disponível em http:// www.bndes.gov.br/SiteBNDES/export/sites/default/bndes_pt/Galerias/ Arquivos/conhecimento/seminario/apl.pdf Acesso em jan/2007. 
SANTOS, G. A. G. dos, e outros. Aglomerações, Arranjos Produtivos Locais e Vantagens Competitivas Locacionais. Revista do BNDES, v. 11, n. 22, p. 151-179, 2004b.

SCHMITZ, H. Eficiência coletiva: caminho de crescimento para a indústria de pequeno porte. Ensaios FEE, v. 18, n. 2, p. 164-200, 1997.

STORPER, M.; HARRISON, B. Flexibilidade, hierarquia e desenvolvimento regional: as mudanças de estrutura dos sistemas produtivos industriais e os seus novos modos de governança nos anos 90. In: BENKO, G. e LIPIETS, A. (Org.). As regiões ganhadoras: distritos e redes, paradigmas da geografia econômica. Oeiras, Portugal: Celta, 1994.

VARGAS, M. A. Aspectos conceituais e metodológicos na análise de arranjos e sistemas produtivos inovativos locais. In: CAMPOS, R. R. (Coord). Nota Técnica 1 do Projeto de pesquisa "Micro e pequena empresa em arranjos produtivos locais no Brasil. Florianópolis: Universidade Federal de Santa Catarina/SEBRAE, 2002a.

VARGAS, M. Proximidade territorial, aprendizado e inovação: um estudo sobre a dimensão local dos processos de capacitação inovativa em arranjos e sistemas produtivos no Brasil. 2002.b. Tese de Doutorado em Economia da Universidade Federal do Rio de Janeiro, Rio de Janeiro, 2002 b. 